\title{
Dependence of optical attenuation on radiation wavelength and waveguide geometry in copper-coated optical fibers
}

\author{
Pavel Cherpak ${ }^{1, *}$, Renat Shaidullin ${ }^{2}$, and Oleg Ryabushkin ${ }^{2}$ \\ ${ }^{1}$ Moscow Institute of Physics and Technology, Institutsky lane 9, Dolgoprudny, Moscow region, 141700, Russia \\ ${ }^{2}$ Fryazino branch of Kotelnikov Institute of Radioengineering and Electronics of RAS, Fryazino, Moscow region, 141190 Russia
}

\begin{abstract}
We demonstrate a novel approach to the determination of optical loss coefficients in metal-coated fibers in a 0.4-1.9 $\mu \mathrm{m}$ wavelength range. It is based on measuring the change of temperature-dependent electrical resistance of the metal coating caused by laser radiation transmitted through the fiber. A number of single-mode and multimode metallized fibers were investigated using several laser sources operating in visible and near infrared ranges. The spectral dependencies of optical losses of copper-coated fibers were experimentally obtained. The region that corresponds to the minimum optical losses is located near $1 \mu \mathrm{m}$ wavelength. The increase of radiation losses in 1.5-1.9 $\mu \mathrm{m}$ region is much steeper compared to polymercoated fibers.
\end{abstract}

\section{Introduction}

Nowadays metallized silica fibers are widely used types of specialty optical fibers. A number of sensors using for laser radiation power measurement [1] or for optical intensity profile measurement [2] were developed based on metal-coated optical waveguides. Several unique highpower fiber laser sources $[3,4]$ were also constructed with the use of active optical fibers with the metal coating. High thermal stability of such fibers allowed to obtain $\mathrm{kW}$-level fiber lasers without external active cooling. Despite its advantages, metallized fibers have significantly higher optical losses compared to optical fibers with polymer coatings. In addition, optical losses strongly depend on the radiation wavelength and fiber geometry. However, there is lack of information in literature concerning the spectral behavior of optical losses of metal-coated fibers with different waveguide geometry. Obviously, for different applications of fibers with metal coatings different parameters such as fiber geometry or source wavelength should be addressed. Therefore, accurate determination of optical loss at different wavelengths is required in order to optimize various devices based on metallized optical fibers.

\section{Measurements of optical attenuation}

A novel approach for the determination of optical loss coefficients of metallized fibers is based on the measurement of the change of temperature-dependent electrical resistance of metal coating conditioned by optical losses. During its propagation through the metalcoated waveguide, some part of laser radiation is scattered and eventually absorbed in the intermediate carbon layer or in the metal coating resulting in its heating. The change of metal coating resistance is measured using high precision ohmmeter. A simplified scheme of experimental setup is shown in Fig. 1. We have investigated several types of copper-coated silica fibers, further referred to as Type-A (thick multimode fiber), Type-B (thin multimode fiber), Type-C (thin single-mode fiber). Main characteristics of these fibers are listed in Table 1. Lengths of the used pieces of metallized fibers were around $0.3 \mathrm{~m}$. In order to study spectral dependence of optical attenuation we have used five laser sources operating at different wavelengths (see Table 2).

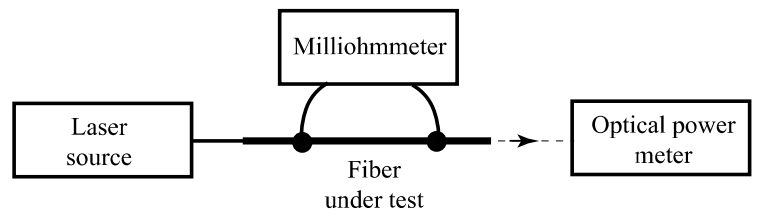

Fig. 1. A simplified scheme of the experimental setup.

Table 1. The main parameters of the studied optical fibers with a copper coating.

\begin{tabular}{|c|c|c|c|}
\hline $\begin{array}{c}\text { Notation of } \\
\text { optical } \\
\text { fibers }\end{array}$ & $\begin{array}{c}\text { Waveguiding } \\
\text { core diameter } \\
(\mu \mathrm{m})\end{array}$ & $\begin{array}{c}\text { Silica } \\
\text { cladding } \\
\text { diameter } \\
(\mu \mathrm{m})\end{array}$ & $\begin{array}{c}\text { Copper } \\
\text { cladding } \\
\text { diameter } \\
(\mu \mathrm{m})\end{array}$ \\
\hline Type-A & 600 & 660 & 780 \\
\hline Type-B & 113 & 125 & 160 \\
\hline Type-C & 9 & 125 & 164 \\
\hline
\end{tabular}

* Corresponding author: cherpak.ps@phystech.edu 
Table 2. Main parameters of the employed laser radiation sources.

\begin{tabular}{|c|c|c|}
\hline Laser type & $\begin{array}{l}\text { Central } \\
\text { wavelength } \\
(\mathrm{nm})\end{array}$ & $\begin{array}{c}\text { Maximum } \\
\text { output power, } \\
\text { W }\end{array}$ \\
\hline $\begin{array}{c}\text { Blue } \\
\text { semiconductor } \\
\text { laser diode }\end{array}$ & 442 & 2.5 \\
\hline $\begin{array}{l}\text { Second harmonic } \\
\text { generation of } \\
\text { Raman fiber laser }\end{array}$ & 589 & 10 \\
\hline $\begin{array}{c}\text { Infrared } \\
\text { semiconductor } \\
\text { laser diode }\end{array}$ & 962 & 30 \\
\hline $\begin{array}{c}\mathrm{Yb}^{3+} \text { doped fiber } \\
\text { laser }\end{array}$ & 1070 & 70 \\
\hline $\begin{array}{l}\mathrm{Yb}^{3+} / \mathrm{Er}^{3+} \text { doped } \\
\text { fiber laser }\end{array}$ & 1550 & 30 \\
\hline $\begin{array}{c}\mathrm{Tm}^{3+} \text { doped fiber } \\
\text { laser }\end{array}$ & 1910 & 40 \\
\hline
\end{tabular}

Using the obtained experimental data together with the solution of the heat conduction problem, taking into account Newton-Richman law of convective cooling, the optical loss coefficients for the copper-coated fibers were calculated. Spectral dependence of optical losses for studied fibers is shown in Fig. 2. Dashed curves show the empirical approximation of the optical loss dependencies on the wavelength. It can be observed, that the lowest optical losses were obtained for the Type-C fiber. This can be attributed to the small diameter of the single-mode (SM) fiber core. Since diffused copper atoms tend to concentrate near the silica-metal interface, the radiation propagating in the core of SM fiber experiences lower scattering on copper atoms compared to multimode (MM) fibers. Type-A fiber demonstrated lower attenuation coefficients compared to Type-B ones. This can be attributed to the lower ratio of the copper coating thickness to the optical fiber diameter of Type-A thick multimode (MM) fiber. It is known [5], that smaller coating thickness corresponds to lower mechanical stress caused by copper layer upon silica and, therefore, to lower microbending losses. Regardless of fiber types the highest losses were observed at $1940 \mathrm{~nm}$ (up to $630 \mathrm{~dB} / \mathrm{km}$ ) and the lowest at $1070 \mathrm{~nm}$ (down to $1,2 \mathrm{~dB} / \mathrm{km}$ ). The increase of optical losses at longer wavelengths can be attributed to the growth of microbending losses [6] and absorption on molecular hydrogen bands [7]. Radiation at shorter wavelengths experiences Rayleigh scattering proportional to $1 / \lambda^{4}$. Overall, it should be noted that optical loss in metal-coated fibers in the short-wave region is of the same order as in polymer-coated fibers, but the increase of radiation losses in 1.5-1.9 $\mu \mathrm{m}$ region is much steeper.

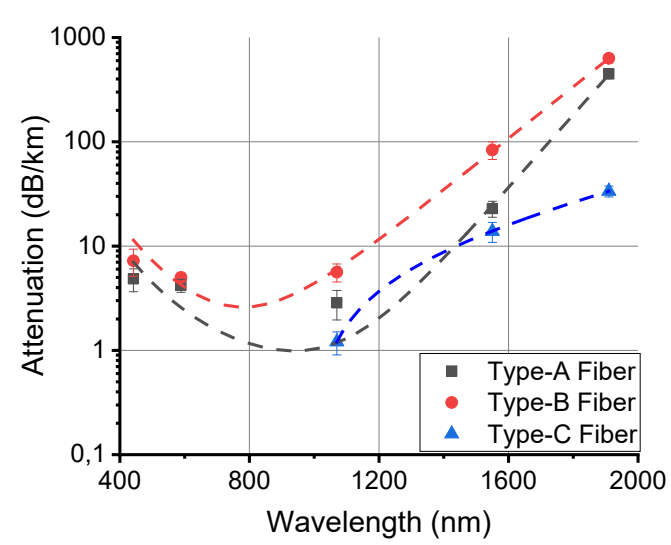

Fig. 2. Spectral dependence of optical loss for the three fibers under test (semi-logarithmic scale).

\section{Conclusion}

In this paper, optical attenuation coefficients of SM and MM copper-coated optical fibers at different wavelengths were determined by measuring the change of electrical resistance of the metal coating. The used method proved to be highly-sensitive and perfectly suited for measuring low optical attenuation in short pieces of metallized fiber. Investigation of spectral dependence of optical losses will help to determine optimal parameters such as fiber geometry or optical radiation wavelength for developing fiber sensors or powerful laser sources employing metalcoated fibers.

We thank the staff of the laboratory №226 of FIRE RAS for the provision of copper-coated fibers for the research.

The work was carried out within the framework of the state task.

\section{References}

1. I. Khramov, R. Shaidullin, O. Ryabushkin, Opt. Eng. 58, 7 (2019)

2. N. Vanyushkin, N. Tereshchenko, A. Kostrov, P. Cherpak, D. Mukhankov, R. Shaidullin, O. Ryabushkin, Seventh European Workshop on Optical Fibre Sensors. 11199, 116 (2019)

3. J.M.O. Daniel, N. Simakov, A. Hemming, W.A. Clarkson, J. Haub, Opt. Express. 24, 18592 (2016)

4. C.X. Yu, O. Shatrovoy, T.Y. Fan, T.F. Taunay, Opt. Lett. 41, 5202 (2016)

5. J.M.O. Daniel, N. Simakov, A. Hemming, W.A. Clarkson, J. Haub, Fiber Lasers XIV: Technology and Systems. 10083, 100831Q (2017)

6. S. Hornung, N. J. Doran, R. Allen, Opt. Quant. Electron. 14, 359 (1982).

7. S.L. Semjonov, V.A. Bogatyrev, A.A. Malinin, 2nd Workshop on Specialty Optical Fibers and Their Applications. 7839, 783912 (2010) 